\title{
Insurance for Civil Liability for Marine Oil Pollution Damages
}

\author{
by Jan C. Bongaerts* and Aline F. M. de Bièvre**
}

\section{Introduction}

With the disappearance of the ultra large and very large crude carriers, spectacular oil pollution accidents at sea are more seldom. Moreover, with the progressive installment of appropriate equipment, deliberate oil spills have also diminished. Oil pollution has not disappeared, however, and still constitutes a serious problem.

This paper deals with the compensation of oil pollution damages. In particular, we investigate the financial arrangements developed by tanker owners and oil receivers, both on a voluntary as well as a regulatory basis.

The paper is set up as follows. Section 1 deals with an overview of the oil pollution problem and its solution. Section 2 presents some data on compensation for oil pollution damages. Section 3 is devoted to a discussion of rules of liability for environmental damages. In Section 4 we outline the functioning of the marine insurance system with respect to oil pollution damages. The final section contains the conclusions.

\section{Oil Pollution at Sea: Problems and Solutions}

Oil pollution at sea has aroused worldwide attention through a number of spectacular tanker accidents causing severe damages to maritime life and to coastal areas. In 1967 the tanker Torrey Canyon grounded off the British coast and lost 120,000 tonnes of crude oil, part of which polluted the coasts of Cornwall and Brittany. In 1978 the tanker Amoco Cadiz broke in two on the rocks off the Brittany coast with a total cargo loss of 220,000 tonnes of crude. The damage to this coast was considerable and raised a wave of protests by inhabitants of the distressed area as well as by environmentalists from all over Europe. Another accident involved the 272,450 dwt tanker Castillo de Bellner which had a midship explosion off Cape Town and then broke in two. The stern portion sank and might eventually leak out its load. The bow section which contained an estimated 100,000 tonnes of light crude, was towed into the open sea and sunk.

\footnotetext{
* Wissenschaftszentrum Berlin, International Institute for Environment and Society.
}

${ }^{* *}$ Associate, S.E.A. Foundation, Delft. 
Especially the disaster involving the Amoco Cadiz increased the concern of governments and shipping interests alike. After the accident with the Torrey Canyon claims were settled out of court and compensation was paid for only part of the clean-up costs (See Volkmar Hartje, 1983, Part V). After the disaster with the Amoco Cadiz, however, the Government of France requested the Legal Committee of IMO to prepare a new set of international rules relating to compensation for damages. Even though the experience of the Torrey Canyon had promoted the development of international rules and agreements, it was felt that stricter regulations were needed and that too many important issues such as the definition of the concept of compensable pollution damage was left to the courts. (See Rouchdy Kbaier and Viktor Sebek, 1985).

Apart from this request the Government of France sued the responsible oil companies in a Chicago court. In 1984 Judge Frank McGarr ruled that Standard Oil of Indiana, the parent company, and Amoco International Oil Company and the tanker owner Amoco Transport Company of Monrovia, the subsidiary companies, are jointly and severally liable for the pollution damage.

Besides these spectacular accidents which received substantial media coverage, there are other sources of oil emission into the ocean. First, we have to mention the deliberate emissions of oil products by ships, either resulting from discharging bilge oil or from tanker washings. Second, we notice oil pollution damage from off-shore installations such as oil rigs and platforms. And third, there is oil pollution from land-based sources. Estimates with respect to discharges from these and other sources are represented in table 1.

Table 1 : Sources of Oil Pollution of the Sea (million Tonnes of Oil)

1973

1981

\begin{tabular}{lllll}
\hline Marine Transportation & 2.1 & & 1.5 & \\
$\quad$ Tanker Operations & & 1.08 & & 0.71 \\
$\quad$ Dry Docking & & 0.25 & & 0.03 \\
$\quad$ MarineTerminals & & 0.0003 & & 0.02 \\
$\quad$ Bilge and Fuel Oil & 0.5 & & 0.32 \\
$\quad$ Tanker Accidents & 0.2 & & 0.39 \\
$\quad$ Non-Tanker Accidents & 0.08 & 0.1 & 0.05 & 0.02 \\
Off-shore Oil Production & 2.7 & & 1.203 & \\
Land-Based Sources & & 0.2 & & 0.2 \\
$\quad$ Refineries & & 0.3 & & 0.2 \\
$\quad$ Non-Refinery Waste & & 0.3 & & 0.3 \\
$\quad$ Municipal Waste & 0.3 & 0.3 & 0.3 \\
$\quad$ Urban Run-Off & 0.6 & & 0.3 & \\
$\quad$ River Run-Off & 0.6 & & 3.3 & \\
Natural Sources & 6.1 & & \\
Atmospheric & & & \\
\hline
\end{tabular}

Source : Y Sasamura, IMCO Conventions Relating to the Prevention of Marine Pollution From Ships, IMCO, London, April 1982. 
Table 1 reveals that overall marine oil pollution is likely to decrease in the next future, if the indicated trend is confirmed. It also shows that the deliberate and not the accidental oil spills do constitute the largest share of total marine oil pollution. In order to deal with the problem of oil pollution on the high seas a multitude of instruments has been designed and implemented. Especially after the Torrey Canyon disaster governments as well as oil transport and trading companies have worked towards the establishment of vessel-source oil pollution prevention and the compensation of damages.

Broadly speaking, we discern three categories of instruments. First, there exist technical regulations with respect to navigational facilities aboard ships as well as with special equipment or processes, such as Crude-Oil-Washing and Load-On-Top, for the purpose of low oil spill tank cleanings. (See David W. Abecassis, 1978, Chapter 2 and Volkmar Hartje, 1983, Part V). These are dealt with by the International Convention for the Prevention of Pollution from Ships of 1973 (MARPOL) and its 1978 Protocol. Both statutes also set maximal discharge limits for pollutants into the sea. Annex 1 contains oil spill emission standards. The MARPOL Convention came into force in 1983. In this paper this instrument will not be dealt with, since we confine ourselves to matters of compensation.

Second, there are insurance schemes arranged by the ship-owners in cooperation with the (re)insurance industry. And third, there are inter-governmental compensation agreements in respect of oil pollution damages. Both compensation schemes are the subject of this paper. They are already covered by a vast amount of literature and we therefore confine ourselves to a brief description of their characteristics. In 1969, under the guidance of the IMO, an international convention was signed. This convention, known as the International Convention on Civil Liability for Oil Pollution Damage, or by its acronym CLC, establishes four principles. (See David W. Abecassis, 1978, for a detailed analysis of CLC).

(a) Liability for oil pollution damages is strict but limited and channeled to the shipowner and no one else;

(b) There is a separate liability for oil pollution damages;

(c) Insurance for such damages must be compulsory;

(d) Claimants may apply to a court of their State if it is a Signatory State.

It is obvious that each of the key terms such as "oil", "ship", etc., is well defined in order to facilitate their use. Yet at the same time these precisions led to exceptions not covered by the CLC Convention. (See Malcolm J. Forster, 1984). A first, but unsuccessful attempt to widen the scope of the liability was made in 1984 at an international IMO conference in London. (See Aline F. M. de Bièvre, 1984, for details on the result of this conference).

Insurance to cover oil pollution damages as stipulated by the CLC Convention is provided by the ship-owners Protection and Indemnity Clubs ( $P \& I$ Clubs), who act as mutual insurers of their members and form an association (the International Group of the P \& I Clubs) to seek reinsurance. (See T. G. Coghlin, 1984). Besides this type of cover, however, ship-owners also give relief through their Tanker Owners Voluntary Agreement Concerning Liability for Oil Pollution, TOVALOP. (See ITOPF, 1984). This privately contracted arrangement actually preceded the CLC Convention until the latter's coming into force in 1975. Today, it is used for offering supplementary compensation for damages not covered 
by the CLC Convention. Examples of such damages are those exceeding the limited liability under the CLC Convention and those created by the pollution of non-persistent oils, such as silicones. These hydrocarbons are not covered by the CLC Convention. Most importantly, TOVALOP covers damages suffered by victims of non-CLC States, provided the shipowner is a party to TOVALOP.

Besides the CLC Convention and the TOVALOP agreement, another compensation scheme known as the International Oil Pollution Compensation Fund was installed in 1971, becoming effective in 1978. It was modified in 1984 during the IMO conference, with a new Protocol being attached. Consequently and in line with the 1984 Protocol to the CLC Convention, the total amount of liability per incident was raised, a broader definition of pollution damages was accepted and the coverage of the Fund was extended to the 200 mile Exclusive Economic Zones of the Signatory States.

The "relationship" between the IOPC Fund and the CLC Convention is as follows. First, the IOPC Fund compensates for damages not covered by the CLC Convention. Hen$c e$, it is used as a supplementary source in case oil pollution damages exceed the share carried by the tanker-owner under the CLC Convention and the TOVALOP agreement. The Fund also pays in the case of an oil spill by a ship-owner with a ship of less than 2000 tonnes since these "small" damages are usually not covered by neither the Convention nor TOVALOP. Second, the IOPC Fund is financed by contributions (levies on each tonne of oil landed) from the oil receivers, whereas the Convention requires compulsory insurance by the ship-owners. Hence the entire compensation scheme consists of a combination of funding and insurance.

In the same way as the CLC Convention was preceded and supplemented by its private counterpart, TOVALOP, the IOPC Fund was also parallelled by a private arrangement called the Contract Regarding an Interim Supplement to Tanker Liability for Oil Pollution, CRISTAL, which was installed in 1971. This Fund was necessary because the IOPC Fund did not become effective until 1978. (See the Oil Companies Institute etc., 1982). Its relation to the IOPC Fund is similar to the relation to TOVALOP to the CLC Convention. CRISTAL offers compensation to victims of oil pollution damages by tankers entered in the TOVALOP agreement when they are unable to recover from other sources, including the IOPC Fund. Like the Fund, liability under CRISTAL is limited. Also like the Fund, there is an arrangement under CRISTAL to compensate for clean-up costs borne by ship-owners after oil spills. In this way both compensation schemes set incentives to ship-owners to take immediate action after an oil spill. CRISTAL differs from the Fund in that it also reimburses the ship-owner's costs of prevention of oil spills, i.e. his so-called threat removal measures. In other words: compensation for costs of measures taken before a possible oil spill may be claimed under CRISTAL but not under the IOPC Fund.

For the last fifteen years compensation for marine oil pollution from ships has been awarded according to this double scheme, involving private and public engagement. At the 1984 IMO conference in London mentioned above, a Protocol was signed containing increases in the limits of liability. They will become operational as soon as international support meets the statutory requirements. Meanwhile the oil receivers launched an unsuccessfull attempt to redistribute the burden of compensation to their benefit and to the disadvantage of the tanker-owners. 
Table 2: Liability Limits of Compensation Arrangements for Marine Oil Pollution Damages: Actual and Proposed Public and Private Arrangements.

\begin{tabular}{|c|c|c|c|c|}
\hline $\begin{array}{l}\text { Compensation } \\
\text { Arrangement }\end{array}$ & $\begin{array}{l}\text { Amount per } \\
\text { Tonne; US \$ }\end{array}$ & $\begin{array}{l}\text { Maximum } \\
\text { Amount }\end{array}$ & $\begin{array}{l}\text { Entry into } \\
\text { Force }\end{array}$ & Remarks \\
\hline TOVALOP & 147 & 16.8 million & 06.10 .1969 & whichever is less \\
\hline CRISTAL & & 36.0 million & 01.04 .1971 & \\
\hline CLC of 1969 & 135 & 15.4 million* & 18.06 .1975 & $\begin{array}{l}\text { *applicable to tankers }>105,000 \\
\text { gross tonnes }\end{array}$ \\
\hline Fund of 1971 & & 49.6 million & 16.10 .1978 & \\
\hline CLC Protocol & $420^{*}$ & 60.0 million $* *$ & not yet & $\begin{array}{l}\text { *applies to tankers }>5,000 \text { gross } \\
\text { tonnes and }<139,999 \text { gross tonnes; } \\
\text { tankers }<5,000 \text { gross tonnes are } \\
\text { liable for minimum flat amount of } \\
3,0 \text { millions }{ }^{* *} \text { applies to tankers } \\
>140,000 \text { gross tonnes }\end{array}$ \\
\hline $\begin{array}{l}\text { Fund Protocol } \\
\text { of } 1984\end{array}$ & & 135 to $200 \mathrm{mio}$ & not yet & upgrading in stages \\
\hline PLATO & 500 to $600^{\S}$ & 60 to $75^{\dagger}$ million & proposed & $\begin{array}{l}{ }_{\text {applies to tankers }>5,000} \text { gross } \\
\text { tonnes and }<104,999 \text { gross tonnes; } \\
\text { upgrading in stages; } \\
\text { tankers }<5,000 \text { tonnes are liable for } \\
\text { a minimum flat amount of } 10 \text { to } 15 \\
\text { million (in stages). } \\
\text { tapplies to tankers } 105,000 \text { gross tonnes }\end{array}$ \\
\hline $\begin{array}{l}\text { NEW } \\
\text { CHRISTAL }\end{array}$ & & $\begin{array}{l}135 \text { to } 200 \\
\text { million }\end{array}$ & proposed & $\begin{array}{l}\text { Proposal in combination } \\
\text { with PLATO }\end{array}$ \\
\hline
\end{tabular}

Sources: Various Official Documents and other Publications quoted in the list of references of this paper. NOTE: The figures for CRISTAL and the 1971 Fund (including those mentioned for the Protocols) do include those of the CLC Convention and TOVALOP respectively. Hence, they should be interpreted as shown in the following example.

The 1971 Fund figure of US Dollars 49,6 million includes the CLC Convention amount of US Dollars 16.8 million. The "Topping-up" capacity of this Fund is therefore equal to US Dollars 49.6 million less US Dollars 16.8 million equals US Dollars 32.8 million.

As a matter of fact, in recent years the oil companies were gradually less affected by the CLC Convention and the TOVALOP compensation arrangements since they had sold off many of their fleets. In this respect they were no longer tied in the self-interests of shipowners and oil receivers and therefore critised their share in the compensation of marine oil pollution damages. As a result the parties to CRISTAL proposed a new TOVALOP scheme called Pollution Liability Agreement among Tanker Owners, PLATO, which would rectify these shortcomings. From table 2 , which provides an overview of all existing and proposed compensation schemes, we see that, under PLATO, small ship-owners would have had to meet higher minimum flat rates and that the maximum liability limit would have been raised, whilst the tonnage to which it applied would have been lowered. PLATO turned out to be unacceptable to the tanker-owners and the scheme was dropped in the summer of 1986. (See Hazardous Cargo Bulletin, July/August 1986). 
Hence, finding an acceptable share of the burden for compensation for oil pollution damages turns out to be critical from the point of view of the victim. It is therefore of importance to find out whether the entire system has in fact operated in a satisfatory way. This issue is picked up in the next section which presents some data on compensation for marine oil pollution damages.

\section{Compensation under CLC and the IOPC Fund - Some Data}

Given the fact that the IOPC Fund as well as the CLC Convention did not become operational until many years after their installment, jurisprudential as well as claims experience with these funds is not overwhelming. Information on the operation of the IOPC Fund, which is a public "institution", is available and encouraging. Between 1978 (date of entry into force) and 1984, the Fund has dealt with some 19 incidents in respect of which claims were made or were in the process of being made. (See R.H. Ganten, 1984).

Besides the IOPC Fund claims were also made against the other compensation schemes. Our interest lies not so much in learning about the amounts of compensation by various criteria such as ship size, flag state, costs of clean-up etc., but only in the shares of compensation paid by ship-owners, oil receivers and victims. Data on these shares have been provided by Henri Smets, 1984, and have been completed for the purpose of this paper. They are represented in table 3.

Table 3: Claims Against Tanker Owners and Oil Receivers

\begin{tabular}{cccccc}
\hline & Total Claims & $\begin{array}{c}\text { Claims Against } \\
\text { Tanker Owners }\end{array}$ & $\begin{array}{c}\text { Claims Against } \\
\text { Oil Receivers }\end{array}$ & $\begin{array}{c}\text { Pollution Costs } \\
\text { of Catastrophes }\end{array}$ & $\begin{array}{c}\text { Uncompensated } \\
\text { Claims }\end{array}$ \\
\hline 1974 & 68.9 & 65.75 & 3.15 & 47.38 & - \\
1975 & 45.8 & 42.82 & 2.98 & 34.30 & - \\
1976 & 99.8 & 96.53 & 2.27 & 80.15 & - \\
1977 & 37.4 & 34.50 & 2.90 & 19.15 & - \\
1978 & 254.2 & 211.40 & 42.80 & 236.38 & $32.18^{*}$ \\
1979 & 149.6 & 78.80 & 71.60 & 178.51 & 28.91 \\
1980 & 165.3 & 61.20 & 104.10 & 194.27 & $28.97^{* *}$ \\
\hline
\end{tabular}

Notes : - All amounts in constant 1983 US Dollars

- All claims up to limits of both private and public arrangements

$\S$ Catastrophes: oil pollution disasters involving costs exceeding 250,000 US Dollars

* Amoco Cadiz

** Tanio

Source: Henri Smets, Dommages causés par les Marées Noires - Incidences Economiques d'une Révision des Limites d'Indemnisation, Environmental Policy and Law, Vol. 12, No. 1/2, February 1984 , pp. $13-36$

Table 3 shows that total claims steadily increased over a relatively short period of time and that the tanker-owners' share diminished to the disadvantage of the shares of the oil receivers and the victims. Especially the truly catastrophic events seem to have created costs for which the compensation scheme was unable to offer full indemnity. Indeed, the costs borne by the victims as represented in table 3 are probably conservative estimates since they are computed under the assumption that claims in respect of non-catastrophic damages 
were compensated by the tanker-owners. Yet this assumption is probably not validated since small tanker-owners need not obtain insurance cover. Hence, damages which, incidentally, may be disproportionally large, caused by those owners, were either covered by the oil receivers or went uncompensated. In fact, PLATO was meant to correct for this escape of liability but the resistance by the tanker-owners to a minimum flat liability irrespective of ship size was fierce (See Seatrade, July 1985).

In conclusion of this short overview, we notice that the compensation system in all its complexity failed to work in the decisive cases for which it was designed and that the purpose of the IOPC Fund Convention of 1971 to offer full compensation to the victims od oil pollution damages was not accomplished. In other words, in cases of low oil spill damages valued at US $\$ 250,000$ or less (at constant value of 1974 ), insurance coverage was usually available and Fund interventions were not required. However, in disastrous events, when Fund money was most welcome, given the prevailing limits, it seemed not to be available in sufficient amounts. This was especially felt after the experience with the accident of the Amoco Cadiz. The question therefore remains whether the institutional arrangements are efficient in the sense that they serve the purposes they are supposed to serve. In order to gain some insight into this question we present two related issues in the rest of this paper. In the next section we discuss some aspects of liability rules for marine oil pollution damages. In the final section we deal with some inefficiencies of the marine insurance market.

\section{Rules of Liability for Environmental Damages}

So far we only presented data on the damages caused by marine oil pollution from ships and on the institutional arrangements set up to provide remedies, pointing out that the latter did not suffice to offer full compensation of the victims. The question remains whether this is due to inefficiencies resulting from the actual operation of the system or else from a shortcoming inherent to the system itself, i.e. to the type of liability rule or the rules of compensation being used. The former type of inefficiency may emerge in case of incomplete information on the insurance market, leading to insufficient vetting and partitioning of the risks covered. This issue will be picked up in the next section. The latter type of inefficiency is of a more fundamental nature and is dealt with by Ingemar Hansson and Göran Skogh, 1987. As these authors notice, many arrangements for reducing the probability of accidents and the compensation of victims contain a combination of instruments, such as a given liability rule, a duty to provide for funds on a first or third party basis in case or damages, rules of safety regulation with respect to equipment and those operating it and the possibility of criminalising the torfeasor's behaviour. Assessing the efficiency of a risk reduction arrangement would therefore involve a screening of each of these instruments separately as well as their joint application. This could be done along the way suggested by Van den Bergh and Faure, 1987, but it would go beyond the scope of this paper. Our analysis remains restricted to an investigation of the efficiency of the arrangement of liability and compensation and it must therefore be taken as "ceteris paribus".

In fact, the case of marine oil pollution is a special one and there are specific reasons for the peculiarity of the actual set-up of the liability and compensation arrangement. First, damages include so-called economic losses as well as damages to ecosystems. Hence, the function of liability rules only applying to private property is limited. Second, damages to third parties or the environment as such are much larger than the damages to the first party. 
Moreover, very often damages to the environment are of a gradually emerging nature, in the sense that the full extent of the damage manifests itself at a date which is considerably later than the date of the accident. In the case of marine oil pollution, restauration of the ecosystem usually takes many years and involves expensive scientific monitoring. And finally, from a pure theoretical point of view, the precise meaning of a restauration operation is unclear whenever the pollution to a marine ecosystem has been detrimental to such an extent, that a "reconstruction" becomes impossible and an alternative "development" of the ecosystem has to be carried out.

In such cases incentives for the prevention of oil pollution damages set to the tankerowners must necessarily have a limited effect on their level of precautionary efforts. Even under a strict liability rule, which in theory forces them to compensate all damages, they will prefer to adopt a given, not necessarily optimal level of care (as shown in the next section) and withdraw from business altogether in case of a disastrous accident.

Third, a serious problem is the absence of a supranational regulatory agency. The only workable arrangement either consists in (sets of) bilateral international agreements or multiparty international agreements. A quick inspection shows that most of them deal with technical matters on safety regulation, whereas very few refer to the establishment of liability rules and compensation schemes. The reason seems to lie in the fact that agreements on technical improvements are more easily accepted by the signatory states since marine insurers will validate them when setting (general) liability insurance premiums. They are thus beneficial to the ship-owners. In contrast, negotiating liability rules in respect of marine oil pollution damages is much more difficult, since the extra costs spent on either (pollution) liability premiums or pollution prevention equipment are not matched by any monetary gains. (See Lloyd's List, 1986, for a general survey of the activities of IMO).

In conclusion, we find that holding solely the tanker-owners liable is inefficient. This follows from the fact that the damages may be a multiple of the ship's value. Even if insurance cover is available, under these circumstances tanker-owners will consider bankruptcy an attractive alternative to the provision of compensation funds whenever a serious accident occurs.

\section{Insurance for Oil Pollution Damages and Reduction of Risk}

After the digression on liability rules with respect to marine oil pollution damages, we turn to the system of marine insurance. As already mentioned ship-owners provide their own insurance coverage through the Protection and Indemnity Clubs. These act as non-profit associations collecting fees (referred to as "calls") from their members in order to reimburse claims brought against them. As T.G. Coghlin, 1984, remarks, experience with these claims cannot be predicted and calls are therefore made at the beginning of each year (starting on February 20 th, "when the Baltic is no longer frozen") by means of so called "advances" which may be augmented by a "supplement". Since supplementary calls turned out be highly volatile in many Clubs, viz. several supplementary calls had to be made in given years, the Clubs have adopted the practice of smoothing out their revenue fluctuations by not returning surpluses to members but using them to reduce deficits in years of bad luck.

Although the $\mathrm{P} \&$ I Clubs are mutual associations, they are nevertheless part of the market place, i.e. they tend to adopt market rules for pricing the risk they cover. Calls are negotiated by the members and the managers of the Clubs and are based upon the claims 
risk each member is supposed to represent. The managers therefore assess the past claims records together with other factors such as the type, size, flag and trading pattern of the ships. Members may also reduce the risk to their Club by limiting the heads of cover or applying for a deductible. Once the calls are set for a given year, advances are determined. As the year passes on, supplementary calls are set in form of a fixed percentage of each member's advance call. Hence the only possibility for a member to have his risk reassessed by the Club is during the annual calls negotiation round and not at the time of setting the supplementary calls.

Finally, the P \& I Clubs are keen to keep a steady membership to safeguard assets. This does not only depend on the level of the calls, but also on services offered. The loyalty of mutual members is such that only a marginal number of them (ten per cent on average) tends to change Clubs for reasons of dissatisfaction with excessive supplementary calls. As to sanctioning bad owners by "kicking them out", their expulsion tends to be extremely difficult as Clubs must be careful about their facts before making allegations about the substandard nature of generally loyal members. Hence, because sanctioning is psychologically difficult, the accepting of new business is very selective and constitutes a form of preventive policy. Clubs may e.g. refuse tankers of fifteen or even twelve years of age or they may do their own ship survey, besides those made by registration offices. However, such measures are not the sole form of risk prevention. In principle, Clubs look into ship management because most owners tend to stick to the same management. Also, as already mentioned, mutual members tend to remain ninety percent the same.

The International Group of the P \& I Clubs was set up as a joint institution of some of the Clubs in order to share risks exceeding a given amount as well as to seek for reinsurance. Apparently some 60 to 70 per cent of the claims is covered by the Clubs, with 20 to 30 per cent covered by the International Group. The remaining part is reinsured. It is obvious, however, that these percentages are valid on average only. If, by way of example, large claims exceeding the amount covered by his Club are made against the owner of a given tanker for several times within a few years, they may be entirely covered by the International Group or even by the reinsurance underwriters. In this case the Club to which this owner belongs has increased its claims risk vis a vis the International Group. Yet if it was successful in passing on the "bad luck" onto the International Group, it has no incentive to reconsider the level of the calls obtained from the given owner. Hence the Clubs are able to "pull and share" each other's claims. (See R.L. Carter, 1979, Chapter 3 for a similar argument).

For this purpose some rules of discipline have been set by the International Group. Nevertheless, discipline may not always be guaranteed, as there is a tremendous breakdown of the risk over an enormous range of insurers, once reinsurance is taken into account. This is due to the fact that each underwriter is protected by a so-called general reinsurance treaty, which determines how much of the risk is retained by the underwriter and how much is laid off. Underwriters who take on what is laid off again make arrangements of retention and lay-off etc. It is obvious that this cascade type of arrangement tends to reduce the transparency of the risks covered in this manner. In fact, in general, underwriters do not know how often a risk has been split in a retention part and a lay-off when they are invited to offer coverage. Therefore they may not be aware of the professional qualification of the initial insurance customer (the ship-owner) until they are faced with a claim. 
Screening or vetting the performance of ship-owners would therefore be needed in order to classify them by claims risk classes. But individual underwriters with an interest in diversifying their portfolios will only have a weak incentive to do so. Since they are forced to allocate their funds over as many small sized risks as possible, they will deliberately minimize the efforts to investigate each individual risk thoroughly. Hence the more they diversify, the less they screen each risk separately. In practice, insurers solve the problem of vetting the risks by offering standardized insurance contracts coupled with standard questionnaires to be filled out by applicants. Another instrument used is a progressive premium system with progression related to an indirect indicator of risk class, such as age and past performance. Such practices are useful in the large retail insurance industry selling health care or life insurance, fire and accident protection insurance and the like. In marine insurance, however, such a standardization is less likely, since the risks are not homogeneous. Underwriters in this branch of the insurance industry thus have to recur to other techniques of screening.

Besides studying the trends in the insurance market they may choose to rely on so-called lead underwriters. These underwriters are experts in offering cover for a particular set of risks, such as oil pollution damages from ships, or from oil rigs, or fire protection aboard ships or oil rigs and the like. Their expertise is visible to the market since they write a sizeable portion of the business in which they specialize. For a non lead underwriter moves of the lead underwriter act as a market signal and therefore help to save information costs. But in following the lead underwriter, his own profitability is connected to the general market trend or to the business cycle of the lead underwriters. Obviously such a strategy cannot replace direct screening of the performance of the ship-owners themselves. Since this is not sufficiently done by the P \& I Clubs, the marine insurance market is imperfect. Indeed, the managers of the $\mathrm{P} \&$ I Clubs do not permanently check the reliability and the professional qualification of their members and their agents, nor do they continuously monitor the quality of their members' ships. They consider themselves as mutual associations with a stable if not longlasting membership. Since they pool the risks without full information on the individual risks, information on the distribution of the risks they cover is irreparably lost.

What this all amounts to is obvious: there are serious market imperfections in the marine insurance industry, since the "first" insurers (the Clubs) who are best placed to investigate the performance of the insured (the member ship-owners) do not collect the relevant information. Consequently the reinsurance industry is not able to correct for this market imperfection. It can only spread the risk as widely as possible. But this does not result in a cost efficient manner of operation. In other words, given these market imperfections, it is more expensive to provide for one dollar of cover than under conditions of market efficiency. (See R.L. Carter, 1979, Chapter 12 for a similar treatment of marine insurance).

Data on the monetary value of marine oil pollution damages and the necessary expenditures for investment in and operation of risk reducing equipment area available to some extent, but their accuracy is heavily disputed. Without entering into detail, we mention a paper by Jim Macneill, 1984, in which he summarizes some data on marine oil pollution prevention costs and damages and clean-up costs. The figures show that the latter are estimated at some US $\$ 500$ million per annum whereas the annual expenditures for oil prevention are estimated to equal US $\$ 1$ billion. The latter figure does include public expenditures 
worth some US $\$ 250$ million for the installment and the operation of navigational aid systems and monitoring systems for the detection of violations as well as for the provision of rescue aid. It does not include public expenses for dirty ballastwater facilities and similar amenities in receiving harbours.

At first sight one might be inclined to conclude on the basis of these figures that tankerowners and governments spend too much on the prevention of oil pollution and that the rule of strict liability for marine oil pollution has led to an excessive reduction of risk. But it is not obious that the tanker-owners bear these costs of prevention due to the rule of strict liability. As mentioned above, other international conventions such as the MARPOL Convention regulate the use of prevention technologies directly. It is therefore impossible to disentangle the effects of the direct regulations and the liability rule.

Moreover, we must distinguish between deliberate and accidental oil spills. Whereas the former ones lead to a much larger amount than the accidental ones, we may dispute whether equipment like Crude-Oil-Washing, Load-on-Top or Segregated-Ballast-Tanks should be considered as risk reducing devices from an insurance theoretical point of view. Indeed, in case all deliberate oil spills would be accurately registered, no cover for the damages resulting from these spills would be obtainable from insurers. Hence, tankerowners would no longer be able to apply the moral hazard principle. As a consequence, all oil spills would henceforth be accidental and insurable. Since the bulk of the tanker-owner prevention expenditures is in deliberate oil spill prevention equipment, which may thus be considered as belonging to the state of the art of the tanker trade, only the remaining expenses should be considered as reducing insurable risks. Estimates on retrofitting entire tanker fleets taken from Volkmar Hartje, 1983, suggest that these remaining expenses are very small.

Lastly, data on the so-called tanker fleet ratings as well as on the distribution of major oil spills by flag show a large variance. Whereas claims for major oil spills from tankers flying the flags of Liberia and Greece amounted to US\$254 million and US\$100 million respectively, claims against tankers from Japan and Norway totalled US\$22 million and US\$ 10 million respectively. These data correspond to some extent to the tanker fleet ratings, giving Japan the best and Norway a high quality mark, quoting Liberia as a good average and putting Greece at the bottom. (See, again, Jim MacNeill, 1984). Hence, efforts to reduce risk are not uniformly spread across countries. If the rule of strict liability operating in the realm of an international insurance market would have led to the exhaustion of all possible prevention strategies, such wide international divergencies would be very unlikely.

Summing up this section we notice that imperfections in the international marine insurance industry are due to insufficient screening of the risk performance by the $P \&$ I Clubs and result in a suboptimal amount of marine oil pollution, which is too high. Moreover, data on the costs of these damages and the efforts to prevent marine oil pollution, while suggesting an excess of such effort over the damages, should be interpreted with care.

\section{Conclusion}

This paper has dealt with the developments of international public regulations and private arrangements concerning the compensation for damages in respect of marine oil pollutioon from ships. After a description of the way these were intiated and interconnected, 
we discussed the political target of offering full compensation to victims. Data seem to suggest that this target is not met in case of severe accidents with very high clean-up costs such as the one involving the Amoco Cadiz in 1978. This is due to the fact that the liabilities assumed by the ship-owners as well as the oil receivers (the oil companies) are limited by statute. Recent developments in the oil business leading to a sale of fleets by the oil companies have also ended the conflict of self-interests they had as ship-owners and oil receivers. As a result the oil companies now require the ship-owners to increase their share of the compensation costs both through an increase of their maximal liability as well as through higher liabilities for smaller ship-owners.

The second point of interest in this paper relates to the compensation arrangement itself. It was found that it would probably be inefficient to hold only the tanker-owners liable for marine oil pollution damages due to existence of "mutual" externalities. Tankerowners inflict risks on oil receivers through possible ship wreckings and oil receivers inflict risks upon tanker-owners since they require the carriage of an inherently hazardous good. Yet an internalisation of these externalities through normal contracts seems not to be possible either, given the competitive conditions and the overcapacity in the oil carriage market.

Lastly, the paper found that the market for marine insurance operates imperfectly, in the sense that screening the risk performance of the ship-owners by their mutual insurance institutions (the P \& I Clubs) is insufficient. As a result, the amount of risk avoiding efforts is suboptimal.

\section{REFERENCES}

ABECASSIS, D.W. (1978): The Law and Practice Relating to Oil Pollution from Ships, London, Butterworths.

ABECASSIS, D.W. (1983): IMO and Liability for Oil Pollution from Ships; A Restrospective, Lloyd's Maritime and Commercial Law Quarterly, 45-49.

BROWN, E.D. (1981): Making the Polluter Pay for Oil Pollution Damage to the Environment: A Note on the Zoe Colocotroni Case, Lloyd's Maritime and Commercial Quarterly, 323-334.

CARTER, R.L. (1979): Reinsurance, Brentford, Kluwer Publishing with the Mercantile and General Reinsurance Company Ltd.

COGHLIN, T.G. (1984): Protection and Indemnity Clubs, Lloyd's Maritime and Commercial Quarterly, 403-416.

Commonwealth of Puerto Rico v. SS Zoe Colocotroni, etc., (1980) 628. Fed. R. 2d. 652 (US Ct. App., 1st. Cir.).

DE BIEVRE, A.F.M. (1984): The International Conference on Liability and Compensation for Damage in Connection with the Carriage of Oil and Other Hazardous Substances by Sea, North Sea Monitor, December, 1-8.

FORSTER, M.J. (1984): The 1984 Protocols to the Oil Pollution Compensation Convention, Environmental Policy and Law, 13, 42-45.

GANTEN, R.H. (1984): The International Oil Pollution Compensation Fund, Environmental Policy and Law, 12, 5-9. 
HANSSON, I. and SKOGH, G. (1987): Liability, Insurance and Safety Regulation, The Geneva Papers on Risk and Insurance, this issue.

HARTJE, V. (1983): Theorie und Politik der Meeresnutzung, eine ökonomisch/institutionelle Analyse, Frankfurt, Campus Verlag.

International Tanker Owners Pollution Federation Limited (1984): TOVALOP, Tanker Owners Voluntary Agreement Concerning Liability for Oil Pollution, London.

KBAIER, R. and SEBEK, V. (1985): New Trends in Compensation for Oil Pollution Damages; Amoco Cadiz Legal Proceedings and the 1984 Diplomatic Conference on Liability and Compensation, Marine Policy, 9, 269-279.

MACNEILL, J. (1984): Impacts of Oil Pollution, Environmental Policy and Law, 13, 87-95.

Oil Companies Institute for Marine Pollution Compensation Limited (1982): CRISTAL, Contract regarding an Interim Supplement to Tanker Liability for Oil Pollution, Hamilton, Bermuda.

(1986): PLATO Called off, Hazardous Cargo Bulletin, 7, July/August.

(1986): Safer Seas - IMO, Lloyd's List, 5-8.

SASAMURA, Y. (1982): IMCO Conventions Relating to the Prevention of Marine Oil Pollution from Ships, London, IMO.

SMETS, H. (1984): Dommages causés par les Marées Noires - Incidences économiques d'une révision des limites d'indemnisation, Environmental Policy and Law, 12, 13-36.

SILVERSTONE, D. (1985): Ship Source Oil Pollution Damage: A Canadian Perspective on Recoverability of Economic Losses and Damage to the Marine Environment, Marine Policy, 9, $108-119$

(1985): The Plato Philosophy, Seatrade, July, 32-35.

TOMCZAK, M. Fr. (1984): Defining Marine Pollution: A Comparison of Definitions Used in International Conventions, Marine Policy, 8, 311-322.

VAN DEN BERGH, R. and FAURE, M. (1987), Negligence, Strict Liability and Direct Regulation of Safety under Belgian Law: An Introductory Analysis, The Geneva Papers on Risk and Insurance, this issue. 